\title{
Artes marciais, formação profissional e escolas de ofício: Análise documental do judô brasileiro
}

\author{
Martial arts, professional education and the apprenticeship system: \\ Documentary analysis of Brazilian judo
}

\author{
A.J. Drigo, S. Souza Neto, J. Cesana, J.B.A. Gomes Tojal
}

\begin{abstract}
RESUMO
Este trabalho tem como objetivo apresentar a constituição das artes marciais no Brasil, em particular o judô, considerando a formação e capacitação do técnico desportivo para a modalidade. Trata-se de uma pesquisa documental, tendo como técnica para coleta de dados a fonte documental. Entre os resultados observou-se que as instituições representantes da modalidade judô, como CBJ, FPJ e LPJ mantêm estruturas semelhantes às escolas de ofício em detrimento de uma formação mais científica relacionada às ciências do desporto. Concluiu-se que o judô brasileiro distancia-se do modelo de formação acadêmica, mantendo-se atrelado às tradições do saber-fazer.

Palavras-chave: formação profissional, escolas de ofício, técnico desportivo, judô
\end{abstract}

ABSTRACT

The aim of this research was to describe the process of professional education of judo coaches in Brazil. In order to do this, documental sources were used as means of data collection. Results showed that highly regarded institutions such as Confederação Brasileira de Judô, Federação Paulista de Judô, and Liga Paulista de Judô all support educational structures that resembles the apprenticeship system, that is, education which provide mostly employment-preparation skills for trained labour, in detriment of education on the application of scientific principles aiming at improving sporting performance. In conclusion, Brazilian judo seems to be kept away from the academic formation model and linked to the know how to do traditions.

Keywords: professional education, apprenticeship system, sports coach, judo

Submetido: 10.05 .2010 | Aceite: 09.12.2010

Alexandre Janotta Drigo. Faculdade de Americana - FAM e Programa de Pós-graduação em Ciências da Motricidade da UNESP; Membro do Núcleo de Estudos e Pesquisas em Formação Profissional no Campo da Educação Física - UNESP, Rio Claro, Brasil.

Samuel de Souza Neto. Departamento de Educação da UNESP; Coordenador do Núcleo de Estudos e Pesquisas em Formação Profissional no Campo da Educação Física - UNESP, Rio Claro, Brasil.

Juliana Cesana. Doutoranda em Ciências do Desporto pela FEF/UNICAMP com financiamento do CNPq; Membro do Núcleo de Estudos e Pesquisas em Formação Profissional no Campo da Educação Física UNESP, Rio Claro, Brasil.

João B. A. Gomes Tojal. FEF/UNICAMP; Vice-Presidente do Núcleo de Estudos e Pesquisas em Formação Profissional no Campo da Educação Física - UNESP, Rio Claro, Brasil.

Endereço para correspondência: Alexandre Janotta Drigo, Depto. de Educação, UNESP/ Rio Claro, Av. 24 A, n 1515, Bela Vista, CEP: 13500-000 Rio Claro - SP, Brasil.

E-mail: alexandredrigo@hotmail.com 
O judô é uma prática desportiva que, oriundo de uma cultura oriental, possui uma estrutura que ora assemelha-se apenas a prática competitiva (federações, ligas e torneios) e ora apresenta-se como reflexo de seu arcabouço cultural - estrutura hierárquica, utilização da língua originária e padrões tradicionais de saudação.

Neste contexto, os elementos desportivos e culturais fazem parte das modalidades que comumente são denominadas de artes marciais no Brasil, nome que de longe lembraria sua origem. Porém, permite que, no discurso de muitos adeptos/praticantes, haja transição no âmbito do binômio desporto/cultura.

O discurso, aparentemente inócuo, no sentido prático, possibilita usufruir dos benefícios e, ao mesmo tempo, mascarar as obrigações na área ou campo, tendo em vista que há investimento do Ministério do Esporte nas entidades dirigentes destas modalidades e a Bolsa Atleta do Governo Federal. Esta última é compartilhada com atletas de artes marciais. Em outro patamar também se registra que não há consenso nacional quanto ao fato dos técnicos de artes marciais terem formação em Educação Física como prevê a Lei 9.696/98 (Congresso Federal do Brasil, 1998). Neste caso, estas lutas não se configuram em desportos, mas como atividades culturais.

Desta forma, destaca-se como problema de estudo o fato de esta "desobrigação" em relação à Educação Física levar ao entendimento de que há um modelo de formação nas artes marciais que dê suporte a demanda social do trabalho com lutas. Porém, por que estudar esta questão?

Desde que foi promulgada a Regulamentação Profissional da Educação Física no Brasil (Congresso Federal do Brasil, 1998), passaram-se mais de 10 anos, podendo-se dizer que, aparentemente, o campo das artes marciais continua um pouco à margem desta história ou seguindo um caminho próprio. $\mathrm{O}$ discurso dicotômico esporte e cultura, embora seja portentoso, pouco respondeu ou desvelou em relação a qual seria a formação do técnico de lutas e se esta estaria adequada à demanda necessária da sociedade atual. Portanto, entender como se dá a relação da formação com o seu modelo de base é o cerne deste texto.

Dessa forma, este trabalho foi organizado tendo como meta apresentar os eixos temáticos ou conteúdos que são essenciais para o entendimento da discussão dos artefatos encontrados em trabalho de campo, lembrando que dada a notória complexidade do assunto, merecedora de exaustivas análises, a mesma não será expandida, ficando restrita a um recorte. Neste, a centralidade da reflexão - as artes marciais, o judô - ficará circunscrita a uma explanação sobre escola de ofício, profissão - mesmo que para isto, haja o risco de, por ora, parecer sintético.

No âmbito desse processo, o ponto de partida da análise do artesanato e sua relação com as artes marciais e lutas está na concepção das "Escolas de Ofício" (Rugiu, 1998). Para Rugiu (1998) estas escolas foram possuidoras de três características particulares que, por ora, são coincidentes e se apresentam nas artes marciais, possuindo pontos comuns entre ambas:

- Os aprendizes em essência aprendem fazendo;

- Apresenta uma imagem valorizada do mestre e;

- As atividades práticas são consideradas tão formativas do caráter quanto os estudos formais.

Considerando que o sentido inicial da educação artesanal pode ser identificado pela relação mestre e aprendiz, base da construção dos saberes, dando sentido ao termo "saber fazer", Cunha (2000) considera que "a educação artesanal desenvolve-se mediante processos não sistemáticos, a partir do trabalho de um jovem aprendiz com um mestre de ofício, em sua própria oficina, com seus próprios instrumentos e até mesmo morando em sua própria casa. Ajudando-o em pequenas tarefas, que lhe são atribuídas de acordo com a lógica da produção, o aprendiz vai dominando aos poucos o ofício" (p. 2). 
Outro ponto interessante abordado pelo autor é a possibilidade de existir normas reguladoras da aprendizagem artesanal, sendo esta controlada pelas corporações de ofício, que exercem controle sobre o mercado de trabalho. Portanto, "os mestres de ofício ficam obrigados a obedecer a critérios como número máximo de aprendizes, tempo de aprendizagem e outros" (p. 3).

Rugiu (1998) conta que as corporações de ofício tiveram o seu desenvolvimento a partir do século XII, tendo o apogeu no século XIV, considerando que o sistema artesanal evoluiu do "sistema familiar", necessidade de produção para subsistência, deslocando-se para o "sistema de corporações". Período em que ocorre o êxodo do artesão para a cidade, passando a produzir para um mercado pequeno e estável, os habitantes urbanos. A relação dos saberes da prática dá-se de pai para filho ou de mestre para discípulo, podendo, ainda, em alguns casos se transmitir através de escolas, organizadas e mantidas por cooperativas ou associações de artesãos.

No geral, como colocou o autor, a experiência artesã pode ser considerada como possuidora de aspectos essenciais de formação, visto como experiência ideal para instruir e se educar, para tornar-se "hábil com as mãos e rápido com a cabeça". Esta "habilidade obtida pelo exercício" era considerada importante para o aprendizado da gramática, religião, geometria, pintura, esgrima, dança, bem como trabalhos em madeira e ferro e outras artes úteis (Rugiu, 1998).

Entretanto, no ciclo evolutivo natural das artes mecânicas e das artes liberais a chegada da "era industrial" provocou uma nova reconfiguração no campo do conhecimento e do trabalho. Os ofícios ou trabalhos especializados ganharam a denominação de ocupação. Porém, as ocupações que tinham na sua base $o$ conhecimento científico, embasando a sua prática e o controle de seus serviços ou do próprio trabalho ganharam o nome de profissão no modelo anglo-americano (Freidson, 1998), enquanto no modelo continental europeu não houve esta distinção, sendo "tudo" considerado profissão (Coelho, 1999).

No Brasil adotou-se o termo profissão de forma indiscriminada, seguindo o modelo europeu, passando no momento atual por uma fase de transição para o modelo angloamericano em que se observa a sua influência nas diretrizes curriculares de formação profissional. Entretanto esta questão não será objeto de análise neste estudo.

No contexto das profissões sabe-se que a Educação Física foi regulamentada pela Lei 9.696/98 (Congresso Federal do Brasil, 1998), tendo como delimitação de seu campo de atuação que: "Art. $3^{\circ}$. Compete ao Profissional de Educação Física coordenar, planejar, programar, supervisionar, dinamizar, dirigir, organizar, avaliar e executar trabalhos, programas, planos e projetos, bem como prestar serviços de auditoria, consultoria e assessoria, realizar treinamentos especializados, participar de equipes multidisciplinares e interdisciplinares e elaborar informes técnicos, científicos e pedagógicos, todos nas áreas de atividades físicas e do desporto" (Congresso Federal do Brasil, 1998).

Assim, as artes marciais (e o judô como desporto) que se configuraram como "ofícios" vinculados, inicialmente, às federações, passaram, no presente, a estar sob a jurisdição da Educação Física. Em contrapartida, há também na sociedade outra legislação, que permite o agrupamento em entidades desportivas com direitos e autonomia que, pautado no desporto ou jogo, tem liberdade de ação perante os pressupostos apresentados do "saber fazer".

Embora haja um entendimento passível de ser considerado em relação à atuação profissional em que está referida a Lei supracitada, não se impediu os diversos questionamentos e reanálises por parte das autoridades, tendo como o exemplo mais concreto a formulação do PL 7370/2010.

Deste modo, frente ao que se apresenta, pelo menos quando se relaciona ao desporto, 
há uma ambiguidade de relações legais que, conforme foi apresentado até o momento, pois há uma legislação que entende a formação profissional e reflete o caráter acadêmico cientifico do "Campo Esportivo", representado pela Lei 9.696/98 (Congresso Federal do Brasil, 1998).

São estas co-existências que permitem os conflitos sociais ao mesmo tempo em que não possibilitam um estudo mais criterioso para a identificação das necessidades do desporto nacional, no seu âmbito geral, determinando a emergência da necessidade de fazê-lo como caráter prioritário ao entendimento da própria identidade da profissão Educação Física.

Perante o exposto, o presente trabalho tem como objetivo apresentar a constituição das artes marciais no Brasil, em particular o judô, considerando a formação e capacitação do técnico desportivo para a modalidade.

\section{MÉTODO}

Trata-se de uma pesquisa documental, tendo como técnica para coleta de dados as fontes documentais. Para tanto as informações sobre a formação do técnico desportivo de judô circunscreveu-se aos documentos de Federações e da Confederação. O universo de documentos consultados e analisados foi selecionado pela internet nos sites da Confederação Brasileira de Judô (CBJ: www.cbj.com.br) da Federação Paulista de Judô (FPJ: www.fpj.com.br) e Federação de Judô do Estado do Rio de Janeiro (FJERJ: www.judorio.org.br). Também foram adicionados documentos da Liga Paulista de Judô (LPJ: www.ligadejudopaulista.com.br) como contraposto das entidades mais antigas de controle do desporto, pois a liga inicia suas atividades em 2000 (Morandini Neto, 2004).

Convém também destacar no desenvolvimento deste processo a vivência do primeiro autor que, além da pesquisa acadêmica, também porta a graduação de faixa preta de judô, sandan (terceiro grau). Desse modo, retomando o objetivo elucidado, qual seja, de apresentar a constituição das artes marciais no
Brasil, em particular o judô, considerando a formação e capacitação do técnico desportivo para a modalidade, os próximos tópicos tratarão desses resultados, assim como da sua discussão.

\section{DESENVOLVIMENTO}

\section{A formação dentro do judô}

O primeiro esforço na busca de documentos ateve-se a investigar a formação do técnico desportivo de judô e suas variações, a saber: instrutor, auxiliar técnico, monitor, treinador. Porém, não foi possível encontrar quaisquer informações na literatura a respeito deste tema.

Como era esperado, os elementos encontrados estavam relacionados à formação do faixa preta, sendo que o credenciamento como técnico - posterior a esta formação existe, porém não são explicitados os critérios (se há) de formação deste, parâmetros que serão retomados mais adiante neste trabalho. Não foram encontrados também os currículos e ementas dos cursos relacionados à formação, e tampouco a temática a ser desenvolvida. Convém lembrar que, para o judô, ainda há a confusão entre treinador/técnico e o professor; da mesma forma sessões de treinamento são confundidas com aulas.

Os primeiros documentos que denotam o vínculo da faixa preta como pré-requisito para a formação de técnico encontrou-se adjuntos às resoluções de registro de academia e renovação do registro, além das resoluções e modelos de ofício para solicitar o Credenciamento de Técnicos da FPJ.

O documento intitulado: "Instruções para pedido de filiação nova na F.P.J." para Entidades Esportivas no ano 2000, coloca as graduações exigidas do "professor" para a filiação, como segue (FPJ, 2000a): "Requerimento e declaração do professor responsável $-13^{\circ}$ - Modelo IV: Se o professor responsável é Faixa Preta $1^{\circ}$ ou $2^{\circ}$ DAN; $14^{\circ}$ - Modelo V: Se o professor responsável é Faixa Preta $3^{\circ} \mathrm{DAN}$ ou acima (...)". A diferença entre os modelos de requerimento é apenas relacionada à faixa em 
si, sendo que no primeiro caso o professor responsável é provisório. Em 2006, novo documento de "Instrução para renovação de registro" é elaborado, porém mantiveram-se os mesmo requisitos, e apenas o "professor" passaria a ser denominado técnico.

Desta forma, em um primeiro momento, a abertura do vínculo com a FPJ estava ligada a ser faixa preta, e posteriormente (em 2006) a ser técnico de judô. Então restaria entender qual é a diferença entre os dois períodos, ou melhor, como se daria a formação técnica para o judô de competição. Os documentos de 2006 se restringiam apenas ao pedido de autorização para exercer a função de técnico, constando de um termo de compromisso assinado. Já em 2007 há mudanças que possibilitam verificar as diferenças que eram impostas até 2006. O documento "Credenciamento de técnicos" de 2007, registrava o motivo da atitude de credenciar os faixas pretas de judô: "A Federação Paulista de Judô, buscando um melhor aperfeiçoamento e direcionamento na conduta dos técnicos em sua área de atuação dentro da área de instrução técnica, estará fazendo um credenciamento de todos os técnicos e auxiliares técnicos para o ano de 2007, que passarão por algumas palestras" (FPJ, 2007a).

Verifica-se, então, que o principal objetivo, senão o único era o de adequar o faixa preta para uma conduta correta na área de instrução técnica, o espaço reservado aos técnicos durante as lutas. Percebe-se, portanto, que realmente existe uma adequação às novas normas, sendo que não há uma formação técnica real ou diferenciada. O texto continua trazendo estas mesmas informações: "Para que o técnico ou seu auxiliar técnico acompanhe seus atletas nas áreas instrução técnica em competições promovidas pela FPJ em 2007, será obrigatório o referido credenciamento, que lhe dará uma carteira específica de técnico ou auxiliar técnico (...); para tanto, o técnico deverá preencher $\mathrm{o}$ formulário (Credenciamento de Técnico) e comparecer juntamente com seus auxiliares técnicos indicados (que poderão ser mais 3 faixas Pretas), no Credenciamento..." (FPJ, 2007a).

Mantendo, ainda, a mesma linha de análise, o documento considera haver palestras durante o dia de credenciamento, de forma que é divulgada sua programação pelo mesmo documento, a saber: "9:30 às 10:00 - Palestra de Arbitragem; 10:00 às 10:30 - Palestra oficiais de Mesa; 10:30 às 11:00 - Palestra Conduta dos Técnicos na área de instrução técnica" (FPJ, 2007b).

Analisando a carga horária e os temas desenvolvidos observaram-se também que as palestras não discutem a formação técnica em si, mas apenas as relações de conduta e arbitragem que, apesar de fazerem parte do conhecimento técnico, espera-se que a formação técnica deva contemplar o conhecimento mais diversificado sobre questões da Metodologia do Treinamento Desportivo e áreas correlatas. Neste caminho, entende-se a relação com os métodos artesanais prevista no estudo sobre as escolas de ofício, onde o elemento "saber fazer" se destaca dentre suas atividades (Rugiu, 1998). Portanto, para estudar a estrutura de formação para o Judô em São Paulo pelo menos - seria importante o estudo sobre a aquisição da faixa preta.

Aprofundando esta questão, quando é estudado o estatuto da FJERJ, registra-se que até mesmo as questões administrativas são de responsabilidade exclusiva dos faixas pretas, conforme o Artigo 16 que insere a norma: "Art. 16 - São impedidos para o desempenho de quaisquer funções ou cargos na FJERJ aqueles: I - judocas registrados na FJERJ de graduação inferior a faixa preta e, ainda, judocas de graduação faixa preta registrados na FJERJ e na CBJ, com menos de três anos" (FJERJ, 2004).

Para a vinculação de entidades desportivas junto a FJERJ, o processo é semelhante ao da FPJ, diferindo apenas em relação às determinações de exigência, que somado ao faixa preta - que no caso do Rio de Janeiro só é aceito acima de terceiro dan -, deverá haver o "nome do professor de Educação Física ou prático de judô, em situação regular com o 
Conselho Regional de Educação Física (CREF), com a FJERJ e com CBJ" (FJERJ, 2007, p. 2).

$\mathrm{O}$ texto define a existência nominal de um professor de Educação Física (o Bacharel ou Graduado não poderia ser necessário também?), mas não define sua competência ou função no processo, nem quem seria o técnico, ou mesmo se ele deverá ou não estar presente nas sessões de treinamento. Interpreta-se, portanto, que a questão é apenas legal, da mesma forma que o impedimento por força da Lei 9.696/98 (Congresso Federal do Brasil, 1998) da atuação como técnico, em alguns estados do país, caso não haja filiação aos Conselhos de Educação Física. A CBJ também insere que: "Art. 19 - Para ter direito de participação nas Competições promovidas pela Confederação Brasileira de Judô, as Federações Filiadas deverão, além de atender às exigências Estatutárias da Entidade Dirigente do Judô Nacional, satisfazer as seguintes condições: (...) VII - Os técnicos das equipes deverão apresentar obrigatoriamente a Carteira de Registro no Conselho Regional de Educação Física - CREF" (CBJ, 2005, pp. 3-4).

Em ambos os documentos encontrados e analisados, não há referências da existência de formação específica para técnico de judô, e a indicação da necessidade de formação em Educação Física, também não é específica, além de legal. Na FPJ a formação em Educação Física dá ao faixa preta menos experiente $\left(1^{\circ}\right.$ e $2^{\circ}$ Dan) o direito de ser técnico, porém com o título de técnico em caráter provisório.

Arremetendo-se, então, às idéias de Bourdieu (1989) percebe-se que o judô possui um espaço social bem definido que procura um isolamento de valores através de formação de faixa preta que será feita durante anos de convívio com a prática e que, esta formação deverá ser condição sine qua non para o desenvolvimento dentro do desporto, fato referendado nos documentos analisados onde há casos que até as funções administrativas deverão ser apenas exercidas por faixas pretas. A faixa preta se torna, portanto, o grande capital específico para o judô que, pelos documentos, é o que qualifica o praticante dentro do espaço social. Outra informação que pode ser introduzida está relacionada ao tempo de permanência no judô que identificaria a formação de um habitus duradouro, isto é, para se formar faixa preta, o tempo de duração e submissão ao espaço social determinaria um comportamento padronizado em relação aos diversos setores que compõe o judô. Porém, o continuum da discussão nos arremete ainda a questão da formação do técnico e suas vertentes, que neste momento evidenciou-se a necessidade de estudar realmente a evolução de faixas até a faixa preta.

Em relação à regulamentação da profissão de Educação Física, num primeiro momento, pelo menos às vistas da $\mathrm{FPJ}$, provocou várias mudanças como no Documento sobre "Credenciamento Técnico: Regulamento", de 2000 (Carvalho Filho, 2000), em que aparentemente não se perpetuaram, tendo em vista os outros documentos já mencionados de 2004 e 2007. Tal documento relata a necessidade de adequação à Lei 9.696/98 (Congresso Federal do Brasil, 1998), mas não dá conta das necessidades de transformação contemporâneas do desporto e a adaptação às novas exigências para um trabalho mais contextualizado em relação à tecnologia de treino. Nestes aspectos o documento enfatiza: "Senhores Professores de Judô, Para atender o disposto no Decreto-lei Federal no 9.696, de 01 de setembro de 1998, sobre a regulamentação da Profissão de Educação Física e criação do Conselho Federal e Conselhos Regionais, após reunião com dirigentes desses órgãos e de outras Federações, especialmente de Artes Marciais, a Federação Paulista de Judô encaminhou solicitação de enquadramento dos professores de Judô, para registro nos respectivos órgãos, em duas condições, aproveitando os trabalhos que vem sendo realizados desde 1995, a saber: imediata e transitória" (Carvalho Filho, 2000). E continua: "Diante do compromisso que a Federação Paulista de Judô estará assumindo com o Conselho Federal de Educação Física para 
poder encaminhar, rapidamente, o registro provisório de todos os Professores de Judô, independente de serem formados ou não em Educação Física, com qualificação, que atuam no Estado de São Paulo, será oferecido o Curso de Credenciamento Técnico (...)" (Carvalho Filho, 2000).

Torna-se interessante observar a adequação aos conselhos de Educação Física, não obstante às críticas surgidas após a implantação da Lei que provocaram modificações, que apesar de pontuais, desestabilizaram a formação artesanal do judô. Neste primeiro momento que aparentemente não se perpetuou - foi evidenciado o aprimoramento através de cursos e estágios para o prático de judô, o que consequentemente colocou o profissional de Educação Física em posição de privilégio.

Os módulos, apesar de serem curtos e superficiais, pelo menos trouxeram à formação de técnico de judô uma possibilidade de contato com outras formas de conhecimento além do prático, se bem que, a condição sine qua non para poder ser credenciado como técnico ainda é o $3^{\circ}$ Dan da faixa preta: "Os interessados deverão, além de atender o disposto no Decreto-lei $n^{\circ} 9.696 / 98$, possuir a graduação mínima de faixa-preta $3^{\circ}$ dan, outorgada pela Confederação Brasileira de Judô ou por ela reconhecida, para serem aceitos como candidatos ao Credenciamento Técnico da Federação Paulista de Judô. No ato da inscrição deverão apresentar o requerimento de inscrição, curriculum vitae documentado, recolher a taxa correspondente e apresentar outros documentos relativos as atividades desenvolvidas no Judô" (FPJ, 2000b).

Por fim, os módulos contidos no texto se diferenciavam do que comumente era exigido para a formação de faixa preta em alguns aspectos, principalmente na questão da avaliação e estágio, sendo que alguns cursos foram diferentes, a saber, com a seguinte programação: "Artigo $2^{\circ}$ - Frequência e Aproveitamento em Cursos (...): 1 - Nague-nokata; 2 - Katame-no-kata; 3 - Fundamentos Técnicos; 4 - Historia, Filosofia e Ética no
Judô; 5 - Arbitragem de Judô; 6 - Noções de Pedagogia para a Prática de Judô; 7 - Educação Física Aplicada na Prática de Judô; 8 Organização Esportiva no Judô; 9 Treinamento Esportivo Aplicado no Judô; 10 Socorros de Urgência aplicados no Judô. Artigo $3^{\circ}$ - Exame de Conhecimentos (...): a) Exame teórico - questões versando sobre os itens 4,5 , 6, 7, 8, 9 e 10 do Artigo 2o; b) Exame prático demonstrações na prática sobre os itens $1,2 \mathrm{e}$ 3 do Artigo $2^{\circ}$. Artigo $4^{\circ}$ - Estágio Prático - (...) Estágio prático específico sobre ensino e treinamento de Judô de, no mínimo, 180 horas em instituições recomendadas pela F.P.J. (FPJ, 2000b).

Como visto, há uma exigência diferenciada da que normalmente era proposta, porém não houve relação direta, com entendimento global da necessidade de modificação em relação às Ciências do Desporto. O que há é uma adequação legal às normas impostas pela legislação que, após o relaxamento das imposições iniciais, aparentemente se desestabilizou, conforme visto nos documentos de credenciamento técnico, que salvo melhor juízo, indicam apenas as exigências em relação ao participar como técnico em torneios oficiais. Com isto, percebe-se o retorno da faixa preta enquanto formação para o judô, continuando o sistema de ofício.

Neste mesmo período, e ainda enfocando as relações entre o desenvolvimento de cursos direcionados às práticas de adequação aos conselhos de Educação Física, surgiu o "Curso para os Profissionais Provisionados em judô" que ao contrário dos anteriores não era de credenciamento técnico, mas sim para provisionados em relação aos conselhos, conforme é relatado no documento:

Com a finalidade de atender as determinações do CONFEF, através das Resoluções $n^{\circ}$ 013/99 e 045/02, para o enquadramento dos profissionais não graduados no que dispõe o Decreto-Lei $n^{\circ} 9.696 / 98$, que regulamenta as atividades próprias dos profissionais de Educação Física, a Federação Paulista de Judô propõe a realização de cursos de atualização 
e/ou aperfeiçoamento aos interessados na modalidade.

De acordo com a orientação do CREF4/SP, poderão ser validados os cursos realizados após 01 de setembro de 1998, portanto, aqueles que tenham frequentado os cursos que serão exigidos nesse processo de regulamentação da profissão poderão ter sua carga horária complementada(FPJ, 2000c).

Esta característica transitória é interessante, pois um fator externo, como a Regulamentação da Educação Física, constituiu a força transformadora da condição artesanal em um primeiro momento, apresentando-se para o judô como reorganizadora de sua estrutura, pelo menos no estado de São Paulo. Continuando o estudo deste mesmo documento, ele irá apresentar o rol dos cursos oferecidos para os praticantes que buscam a tornar-se provisionados e assim estar de acordo com o previsto em lei. Os temas abordados foram: "Rol dos cursos - 1 - História e filosofia do Judô - 04 horas; 2 - Fundamentos técnicos de nague-waza - 20 horas; 3 - Fundamentos técnicos de katame-waza - 16 horas; 4 Aperfeiçoamento em nague-no-kata - 20 horas; 5 - Aperfeiçoamento em katame-no-kata - 12 horas; 6 - Noções de pedagogia e educação física infantil na prática do Judô - 12 horas; 7 Noções de socorros de urgência nas atividades de judô - 04 horas; 8 - Treinamento esportivo aplicado ao judô - 08 horas; 9 - Organização esportiva do judô e ética profissional - 04 horas" (FPJ, 2000c).

Nesta divisão, há ainda o predomínio de atividades relacionadas ao "saber fazer", que interagem com as práticas de movimentos de lutas e conceitos orais do judô, e também apresentam uma carga horária menor de elementos teóricos que, apesar de serem restritos para grande parte dos provisionados senão a totalidade - foram informações que acessaram pela primeira vez em sua formação de judocas. Esta superficialidade temática poderia ser um indício da transformação da escola de ofício em direção ao modelo de formação acadêmica. Porém, esta afirmação é impossível de ser verificada devido a este ser o momento estudado. Só com o passar de anos se poderá responder a esta questão. Para o momento pode-se afirmar que:

- A Regulamentação da profissão Educação Física (Lei 9.696/98) desestabilizou, em um primeiro momento, a formação tradicional de faixa preta.

- Normas internacionais do judô, expressas pelas regras, motivaram adequações para a terminologia de professor para técnico, porém a formação deste técnico ainda é restrita ao termo, sem a devida adequação acadêmico-científica.

- A única relação possível de ser observada da demanda de recursos humanos para o judô - técnicos, dirigentes, preparadores físicos, monitores e treinadores, entre outros dá-se pela formação de faixa preta e de suas "graduações", onde é percebido que o acúmulo de dans (graus) corresponderá ao acúmulo do capital específico exposto por Bourdieu. Portanto, estudar a relação de formação para o judô, neste momento, não é outra coisa senão estudar $\mathrm{o}$ processo de formação de faixa preta.

\section{Os documentos e a formação do faixa preta de judô}

Os documentos que fazem referência à formação de faixas pretas da instituição CBJ não se encontram disponíveis, e também seus requisitos e critérios. Porém, os documentos da FPJ sobre formação e da FJERJ apresentam a justificativa para o fato de, segundo a FPJ: "A promoção de grau para faixa preta de judô é competência exclusiva da Confederação Brasileira de Judô que, por delegação específica, autoriza a Federação Paulista de Judô a realizar exames de graduação até o $5^{\circ}$ (quinto) Dan, aos candidatos registados por entidades filiadas em sua jurisdição" (FPJ, 2006). 
Já a FJERJ é mais específica, definindo em seu "Regulamento para promoção de dan" que: "Art. 2 - Os exames à shodan, nidan, sandan e yondan a partir de 1993 estão sendo, somente, realizados pelas Federações, de acordo com o ato 06/93 da Confederação Brasileira de Judô" (FJERJ, 2007, p. 18).

Entende-se, então, que há uma regionalização em relação à promoção de faixa preta e que, apesar de serem efetuadas as promoções pelos estados, há o controle central da CBJ, que outorga e valida os exames. Há, ainda, estudando o documento da FJERJ (2006), uma interferência internacional da Federação Internacional de Judô (FIJ) no processo. O documento afirma: "Seção II; Art. 38, XX outorgar graduação de faixas, instituindo e regulando a matéria, respeitadas as normatizações emanadas da FIJ e da CBJ" (FJERJ, 2007, p. 20).

Conforme ainda este documento (FJERJ, 2007), o praticante deverá passar no mínimo cinco anos e seis meses de treinamento para chegar à faixa preta, caso tenha aproveitamento total em todas as fases e os exames forem coincidentes com todos os períodos de carência. Então a aquisição de conhecimentos da faixa branca até a faixa marrom é exclusivamente prática, ou seja, de habilidades e normas de etiquetas pertinentes ao judô.

Tradicionalmente, no Japão, as saudações são feitas sem nenhum contato físico. Portanto, apertos de mão, abraços ou batidinhas nas costas não são necessários dentro do Dojo. Por causa dos costumes ocidentais, porém, é comum vermos a saudação (Ritsu-Rei) muitas vezes ser seguida de um aperto de mão. Quando estiver cumprimentando um Sensei, espere que qualquer atitude mais calorosa parta dele, não tomando nunca a iniciativa (Morandini Neto, 2004, p. 10).

Estas normas técnicas são aprendidas pelos judocas de forma prática, isto é, através da vivência e convivência duradoura com o treinamento de judô, e está apontado claramente como um dos princípios básicos das Escolas de Ofício, que durante a discussão, esteve sempre adjacente ao exposto: o aprender fazendo, o saberfazer esteve sempre relacionado à formação do judoca. Isto fica claro pela LPJ quando expõe: "A ética e a etiqueta dentro do Judô estão diretamente associadas à sua expressão máxima: a educação, a prosperidade e o respeito mútuo. Como instrumento de educação, o Judô é formado por um conjunto de atitudes e posturas, que tem sua prática associada tanto à técnica quanto à filosofia. Do respeito a esse conjunto de atitudes e posturas é que depende a sobrevivência da essência e do verdadeiro espírito do Judô. Normalmente o judoca aprende a se conduzir dentro do Dojo de forma intuitiva, vendo e repetindo posturas e atitudes. A Etiqueta vem sendo transmitida, muitas vezes informalmente, de geração para geração, dentro dos princípios que deram origem ao Judô" (Morandini Neto, 2004, p. 10).

Vale ainda salientar que a LPJ é a entidade mais nova das analisadas, tendo seu início no ano de 2000 e que, devido a isto deveria ser a mais diferenciada e inovadora, porém não foram observadas mutações, mas a manutenção - até certo ponto mais severa - do processo artesanal.

Com o entendimento do caminho ao faixa preta apresentado, cabe agora a verificação dos exames e quesitos para chegar aos graus de formação do desporto estudado.

Os documentos da FJERJ descrevem o tempo de formação em cada etapa, conforme apresentado anteriormente, e também os quesitos administrativos para participar no exame, como a necessidade de filiação nas entidades - FJERJ e CBJ - e os critérios para participar do exame: "Art. $4^{\circ}$ - Os candidatos à shodan, nidan, sandan e yondan deverão, no ano em que irão prestar exame: a) se inscrever com a autorização do professor de sua agremiação, que deverá estar com a sua situação regularizada na FJERJ e CBJ; b) ter carência para promoção no ato da inscrição; c) frequentar integralmente todos os módulos da 
Federação de Judô do Estado do Rio de Janeiro, podendo ter apenas uma falta" (FJERJ, 2007, p. 18).

Neste momento aparece claramente a questão do "professor", onde a autorização do mesmo é condição para prestar o exame. Isto denota outra característica da escola de ofício, a presença do "mestre" no processo. Impreterivelmente, após aprender fazendo, a figura do "mestre" estará presente nas relações entre o aluno e a entidade administrativa, sendo que seu aval será o condicionante para a ascensão do praticante no espaço social do judô. Esta necessidade é tão evidente que o mesmo documento considera que, caso não houver um "professor" mais graduado que o candidato na associação que pertence, outro "mestre" deverá ser responsável pela sua indicação: "Parág. $2^{\circ}$ $\mathrm{O}$ candidato à promoção de Dan, filiado à agremiação federada à FJERJ, que não tenha no professor responsável a graduação mínima exigida, ou seja, a graduação superior à do candidato para regularizar a sua inscrição no processo de exame para promoção, poderá solicitar a outro professor, de outra agremiação federada à FJERJ e com graduação reconhecida por esta e pela CBJ, que assine os respectivos formulários e compareça às reuniões programadas, dessa forma atendendo a essa exigência" (FJERJ, 2007, p. 18).

Outro ponto que encerra as informações pertinentes a este documento é a participação voluntária, no sentido da remuneração, e obrigatória enquanto participação - para o exame de faixas - de atividades que contribuam com a FJERJ, a saber, trabalhar como oficial de mesa ou árbitros de competições oficiais da federação. Observam-se duas relações com o referencial teórico de Bourdieu (1989), que inicialmente é o contato mais aprofundado em relação ao espaço social, ou seja, a participação direta em relação à parte administrativa dos eventos de judô que, mesmo superficialmente, diferencia-se das faixas anteriores. Outra relação percebida é a do acúmulo progressivo de capital específico dentro do desporto, onde passa-se primeira- mente na função de mesário, e após isso na função de árbitro, formando um novo dimensionamento de fatores hierárquicos dentro da modalidade, que além das faixas, exige a progressão de atividades de arbitragem - diferentes de outros desportos, onde a arbitragem é opção pessoal; neste caso ser árbitro é obrigação - desde a função de oficial de mesa até as graduações dentro da própria arbitragem, a saber: "Art. 12 - O Quadro de Árbitros será formado por Árbitros de acordo com a seguinte classificação da Federação Internacional de Judô: Estadual - Nacional C Nacional B - Nacional A - Aspirante A Fij C Internacional $\mathrm{C}$ - Internacional $\mathrm{B}$ e Internacional A" (FJERJ, 2007, p. 24).

Os módulos e os cursos oferecidos pela FJERJ não são discriminados. Apenas há menção de estágios técnicos apresentados, por exemplo, nos anexos do Boletim Oficial 010/07 de 22 de maio de 2007 (Drigo, 2007) que indica a execução destes cursos, porém não é relatado o seu conteúdo.

Por outro lado, a formação de faixas pretas da FPJ é mais explicada em seus documentos, constando de informações semelhantes ao da FJERJ quanto às carências e pré-requisitos que seguem as determinações da CBJ - e também, aumentam os conteúdos informativos para a análise. Infelizmente a LPJ em sua apostila de graduação faz menção apenas às terminologias, normas e imposições de comportamentos, alguns até deselegantes para a modernidade, porém que focalizam muito a formação artesanal e até mesmo o tipo de estrutura de poder existente nas relações, onde fica difícil a identificação como sessão de treino ou uma atividade de cunho diferenciado do desporto. Isto se torna estranho, sobretudo para uma entidade que começou a sua atividade há apenas oito anos. Com relação a isto o que pode ser refletido é a característica pós-moderna da sociedade atual, pois conforme se apresentam os elementos da LPJ, percebemos que há um direcionamento para uma prática de desenvolvimento religioso ou cultural em detrimento de um desenvol- 
vimento desportivo. Algumas normas são claras, foram selecionadas, pois chamam atenção quanto às atitudes: "- Nunca se atrase para o início de um treino; - Não converse ou faça brincadeiras; - Treine com o máximo esforço e dedicação; - Quando estiver em pé, ouvindo alguma explicação ou observando o treino, a postura correta é Shizen-Hontai, ou seja, com o corpo ereto e as mãos soltas ao lado do corpo. Cruzar os braços, apoiar as mãos na cintura ou cruzá-las atrás das costas denota falta de interesse ou respeito; - Exceto por estar extremamente cansado ou machucado, nunca recuse treinar com um Sensei; Trate os instrutores, superiores e colegas com respeito e cortesia" (Morandini Neto, 2004).

As questões apontadas dão ênfase aos comportamentos e atitudes dentro de uma sessão de treino de judô que, sob olhar pedagógico sobre o desporto, não faltam indagações sobre as atitudes, como: por que de não conversar ou fazer brincadeiras? Estão se relacionando a crianças, jovens ou adultos? As estratégias de utilização de jogos ou até mesmo lúdicas deverão ser desconsideradas para o treino de judô? Por que muitas vezes as posturas normais são consideradas erradas? Como são feitas as avaliações de desgaste físico ou stress físico para as exigências de continuar treinando mesmo cansado? Qual o papel do Sensei, treinador ou líder? Porque o termo "superiores"? As prováveis respostas destas perguntas estão relacionadas com o domínio esperado pela ação da formação artesanal e a estruturação do hábito de treino durante a convivência com a modalidade. Os tipos de relações sociais encontram-se de acordo com o esperado. Interessante também é o apontamento do atraso ao início do treinamento que, conforme é apresentado pelas normas: "Caso o Sensei (responsável pelo treino ou de alta graduação) adentre o Dojo após o início do treino, as atividades deverão ser interrompidas pelo mais graduado (Mate). Será dado o comando Kiotsuke (todos se voltarão para o Sensei). Após o comando 'Rei' todos saudarão o Sensei em Ritsu-Rei” (Morandini Neto, 2004, p. 11).
Está clara então a questão da relação com o "mestre artesão", onde ele é a fonte do saber, e a ele deve-se o respeito, já que mesmo se atrasando, os discípulos devem interromper sua sessão de treino para fazer a reverência. Continuando com as informações sobre a relação entre mestre e discípulo: "Ao treinar com os Senseis, faça isso da maneira mais solta possível. Deixe que ele faça sua pegada (KumiKata), demonstrando respeito e consideração. Quando estiver descansando ou observando o treino, jamais dê as costas para Shomen" (Morandini Neto, 2004).

O Shomen estaria relacionado ao altar à frente do local de prática destinado ao criador do judô ou mestre já idoso ou mesmo falecido que continua responsável pelo local de prática.

As informações da LPJ auxiliam o entendimento da estrutura de ofício relacionado às práticas de um judô mais tradicional. Porém, enquanto desporto de competição, a FPJ deve apresentar diferenças, pois como participante da CBJ, responsável pelo judô competitivo brasileiro, pelo menos as normas internacionais são aceitas - como as diferentes cores de kimonos - e a estrutura competitiva deve ser mais fundamentada. Em relação à estrutura de formação de faixa pretas da FPJ, como dito anteriormente, foram analisados os regulamentos da entidade dos anos de 2000, 2004 e 2007.

Os documentos são muito semelhantes e apresentam diferenças mínimas, principalmente as dos anos de 2004 e 2007 que mantêm a mesma estrutura e conteúdo. Como é de praxe, a norma para inscrição são as mesmas para as carências e indica, como na FJERJ, a mesma necessidade da permissão do "professor", porém há ainda a necessidade do aval de um mestre intermediário - delegado regional - para dar entrada na inscrição do exame: "Artigo $4^{\circ}$ - Parágrafo único: A ficha de inscrição deverá conter a declaração do Professor Responsável o qual dará a sua autorização, atestando que o candidato possui idoneidade moral e se responsabilizando pelo mesmo, e bem como, receber parecer do 
Delegado Regional ou de um membro da Delegacia, especialmente designado para essa finalidade" (FPJ, 2004, 2006, 2007a).

A FPJ é a primeira, pelos documentos analisados que define claramente o conteúdo exigido para o exame de formação de faixa preta, definindo este como: "Artigo $7^{\circ}$ - Para candidatos do $1^{\circ}$ ao $5^{\circ}$ DAN, o Exame de Graduação deverá abranger as seguintes áreas: 1) Conhecimento teórico - História, filosofia e ética do Judô, princípios de ensino e pedagogia do Judô, organização esportiva do Judô, noções de socorros de urgência, arbitragem de competições de Judô; 2) Conhecimento prático - demonstrar habilidades técnicas, conforme consta do Artigo $10^{\circ}$ do Regulamento de Promoção e Controle de Faixas da CBJ. Parágrafo único: Os candidatos do $3^{\circ}$ ao $5^{\circ}$ DAN deverão ainda, demonstrar experiência no ensino dos fundamentos básicos do Judô destinado aos iniciantes (até $1^{\circ} \mathrm{Kyu}$ ) (FPJ, 2004, 2006, 2007a).

Munido desta informação é confirmada a relação predominante do domínio prático na formação de faixa preta e, ao que ser refere ao domínio teórico, está centrado em elementos formativos direcionados a uma formação específica, podendo considerar o único elemento de formação geral o curso de primeiros socorros. Pela observação do rol de elementos que são cobrados para o exame, pouca ou nenhuma relação é feita com a Metodologia de Treino ou Ciências do Desporto. A questão da prática da academia, do cotidiano no tatame que moldam o habitus do judô imperam em relação ao exame, tendo até mesmo dominância quando se trata do conhecimento teórico, pois estamos dentro daquilo que se denomina "campo" e illusio (Bourdieu, 1989). Isto é refletido por toda a preparação e cursos válidos serem de caráter exclusivo da FPJ: "Artigo $8^{\circ}$ - Compete à Federação Paulista de Judô ministrar cursos e oferecer estágios nas áreas dos conhecimentos teórico e prático, dispostos no Artigo $7^{\circ}$, visando a preparação dos candidatos" (FPJ, 2004, 2006, 2007a).
Outra informação semelhante ao já relatado na FJERJ ocorre referente às atividades de mesários ou arbitragem, que na FPJ são denominadas como "atividades gerais", e que mantém a mesma relação da inserção obrigatória e progressiva no espaço social do judô, que se apresenta como avaliação anterior à inscrição para o exame: "Artigo 14: A avaliação das atividades gerais refere-se à iniciativa e desempenho do candidato em atuações de interesse ao desenvolvimento do Judô, a nível regional, estadual, e nacional. Essa avaliação será feita através da atribuição de pontos (...)" (FPJ, 2004, 2006, 2007a).

No geral há nas estruturas de ofício (Corporações de Ofício) o fato de que não será o próprio mestre que avalia a capacidade do artesão ou judoca, mas sim, é formada, na capital, uma banca examinadora com mestres externos ao aprendizado. "Artigo $9^{\circ}$ - O exame será realizado através de provas escritas e demonstrações práticas, de acordo com a graduação pretendida, sob a responsabilidade de uma Comissão Examinadora, especialmente nomeada para essa finalidade; (...) com apresentação pública, submetendo-se o candidato à avaliação de uma Banca Examinadora composta por Professores, devidamente qualificados e designados para essa finalidade (FPJ, 2004, 2006, 2007a).

Finalmente, ressaltando as discussões anteriores da relação entre os Conselhos de Educação Física e o judô, selecionando os cursos oferecidos nos documentos da FPJ indicam os seguintes tema em 2000: a) arbitragem e/ou oficiais de mesa; b) noções de primeiros socorros; c) organização esportiva do judô; d) história, filosofia e ética do judô; e) noções de pedagogia aplicada ao judô; f) fundamentos e técnicas em geral; g) kata; h) educação física infantil no judô; i) treinamento esportivo aplicado ao judô (FPJ, 2006).

Em 2004, os cursos eram: a) oficiais de mesa; b) arbitragem; c) história e filosofia do judô; d) organização esportiva do judô e noções de primeiros socorros; e) noções de pedagogia e educação física infantil aplicadas 
ao judô; f) fundamentos de técnicas em geral (FPJ, 2004). Em 2007 os cursos foram: a) oficiais de mesa; b) arbitragem; c) história e filosofia do judô; d) organização esportiva do judô e noções de primeiros socorros; e) noções de pedagogia e educação física infantil aplicadas ao judô; f) fundamentos de técnicas em geral (FPJ, 2007b).

Como observado anteriormente, após o momento inicial de adequação legal, as mudanças pontuais principalmente em relação à formação do técnico desportivo, acabou regredindo. A retirada do curso de 2000, "treinamento desportivo aplicado ao judô", e a aglutinação dos cursos de pedagogia e Educação Física infantil aplicada ao judô, são representantes do possível retrocesso.

\section{CONCLUSÕES}

Neste estudo enfatizou-se a questão das semelhanças entre o espaço social do judô e as escolas de ofício, onde até o momento existiram apontamentos sobre capital específico, mas foi enfatizando o artesanato. Com isto percebeu-se uma relação clara nos elementos:

- Os aprendizes judocas aprendem essencialmente fazendo;

- Apresentam entidades semelhantes às Corporações de Ofício (CBJ, FPJ, FJERJ, LPJ);

- Há um poder máximo centralizado, que aparece adjacente, mas dita as normas do ofício - conforme o Vaticano foi para as estruturas medievais de Ofício - neste caso é a FIJ;

- A figura do mestre é claramente responsável por toda formação do aprendiz, tanto formal como legalmente.

- Existe uma estrutura semelhante à religiosidade que há nas Corporações de Ofício, só que é representada, neste caso, pela religiosidade ou "filosofia" oriental;

- E, por fim, a apresentação da "obraprima" - os movimentos técnicos - a uma banca examinadora formada por outros mestres que avaliarão o aprendiz na capital do estado em evento específico.

Concluiu-se, portanto, que no Brasil, em relação à estrutura acadêmica da Educação Física, ainda há uma lacuna de legitimidade e interpretação das necessidades da prática no que diz respeito à formação da competência do técnico ou do mestre de judô, tornando-se uma questão mal resolvida que até o momento não foi abordada de forma clara, nem no âmbito das federações e confederações, ou resolvida pelo campo acadêmico, não havendo comunicação entre estas instâncias. Desta forma, a perspectiva de trabalho com judô fica, por ora, restrita apenas à prática do artesão, à experiência e ao bom senso.

\section{REFERÊNCIAS}

Bourdieu, P. (1989). O poder simbólico. Lisboa: Difel. Carvalho Filho, F. (2000). Carta aberta: 10 de março de 2000. São Paulo: Federação Paulista de Judô.

Coelho, E. C. (1999). As profissões imperiais: Medicina, engenharia e advocacia no Rio de Janeiro, 18221930. Rio de Janeiro: Record.

Confederação Brasileira de Judô - CBJ (2005). Regulamento de competição. Rio de Janeiro: Autor.

Congresso Federal do Brasil (1998). Regulamentação da profissão de Educação Física e cria os respectivos Conselhos Federal e regional de Educação Física. In Lei $n^{\circ} 9.696$, de $1^{\circ}$ de setembro de 1998, Diário Oficial da República Federativa do Brasil. Brasília, DF, Brasil: Autor.

Cunha, L. A. (2000). O ensino de oficios artesanais e manufatureiros no Brasil escravocrata. São Paulo: Editora UNESP.

Drigo, A. J. (2007). O judô; do modelo artesanal ao modelo científico: Um estudo sobre as lutas, formação profissional e construção do Habitus (Tese de Doutorado em Educação Física). Universidade Estadual de Campinas, Campinas, Brasil.

Federação de Judô do Estado do Rio de Janeiro FJERJ (2004). Estatuto social da FJERJ. Rio de Janeiro: Autor.

Federação de Judô do Estado do Rio de Janeiro FJERJ (2007). Regulamento técnico e administrativo da FJERJ. Rio de Janeiro: Autor.

Federação Paulista de Judô - FPJ (2000a). Instrução para pedido de registro na F.P.J: Entidade vinculada. São Paulo, Autor. 
Federação Paulista de Judô - FPJ (2000b). Credenciamento de técnicos: Regulamento. São Paulo: Autor.

Federação Paulista de Judô - FPJ (2000c). Curso para provisionados em Judô. São Paulo: Autor.

Federação Paulista de Judô - FPJ (2004). Exame de graduação para faixa-preta de judô. São Paulo: Autor.

Federação Paulista de Judô - FPJ (2006). Exame de graduação para faixa preta. São Paulo: Autor.

Federação Paulista de Judô - FPJ (2007a). Credenciamento de técnicos. São Paulo: Autor.
Federação Paulista de Judô - FPJ (2007b). Credenciamento de técnicos: Programação. São Paulo: Autor.

Freidson, E. (1998). Renascimento do profissionalismo: Teoria, profecia e política. São Paulo: Editora da Universidade de São Paulo.

Morandini Neto, A. (2004). Liga Paulista de Judô: Apostila de graduação. São Paulo: Liga de Judô Paulista.

Rugiu, A. S. (1998). Nostalgia do mestre artesão (1 ed.). Campinas-SP: Autores Associados.

(oc) EY-Nc Todo o conteúdo da revista Motricidade está licenciado sob a Creative Commons, excepto quando especificado em contrário e nos conteúdos retirados de outras fontes bibliográficas. 